\title{
Effect of Different Chemical Treatments for Breaking Seed Dormancy in Sesbania spp.
}

\author{
Kuldeep Singh ${ }^{1}$, Ruchi Sharma ${ }^{1 *}$, Rajesh Gera ${ }^{1}$, Jagdish Parshad ${ }^{1}$ and \\ Shahid Ahmad Padder ${ }^{2}$ \\ ${ }^{1}$ Department of Microbiology, Chaudhary Charan Singh Haryana Agricultural University, \\ Hisar-125004, India \\ ${ }^{2}$ Division of Plant Pathology, Division of soil Science, SKUAST-Kashmir Srinagar, India \\ *Corresponding author
}

\section{A B S T R A C T}

\begin{tabular}{|l|}
\hline Ke y w o r d s \\
$\begin{array}{l}\text { Germination, Seed } \\
\text { dormancy, Sesbania } \\
\text { spp, Soaking, } \\
\text { Temperature }\end{array}$ \\
\hline Article Info \\
\hline $\begin{array}{l}\text { Accepted: } \\
\text { 20 September } 2020 \\
\text { Available Online: } \\
\text { 10 October } 2020\end{array}$ \\
\hline \hline
\end{tabular}

\section{Introduction}

The genus Sesbania contains about 70 species prevalent over tropical and subtropical regions, including annual, perennial, herbaceous shrubs and trees. Sesbania spp. are native to Asian countries such as India, Malaysia, Indonesia and Philippins where it is generally growing on the dikes between rice paddies along roadsides and in backyard vegetable gardens. In and around India, many species of Sesbania are widespread with abundance of $S$. speciosa, S. grandiflora, $S$. sesban (L.), S. bispinosa (Jacq.), S. cannabina
(Retz.), S. aculeata and S. rostrata (Bhat, 2003). Most of the Sesbania spp. are described as soft, semi or slightly woody with 1-4 m height. These grow quickly and rapidly accumulate nitrogen $\left(\mathrm{N}_{2}\right)$ rich biomass suitable for soil fertility replenishment and also provide fuel wood, fodder and mulch.

During living stage of plant the seedling phase is a critical point, helpful in investigation the natural and developmental story of higher plants (Duke and Polhill, 1981). To sustain extensive periods of unfavourable environment, the seed is well set 
mainly in a dry state. Without germinating, seeds can survive for an extended period more over as stored in dehydrated environment otherwise once covered under the soil. Seed enters a dormant position to optimize germination over time. Due to dormancy in seeds of Sesbania spp., seed reservoir in soil helps endurance and perpetuation in different conditions. Dormancy in seeds is forced by single or more of the kernel, endosperm and protective tissues that be related to double genesis and stand for two ploidy zone. Via avoidance of gas swap over, water uptake, light dispersion and escape of determent from the embryo, thick seed coat inhibits seed germination (Taylorson and Hendricks, 1977). To defeat state that are harsh for seedling, seed dormancy allows seeds to be established and is therefore significant for agriculture and plant ecology. Dormancy prevents pre-harvest germination as well. Failure of a viable seed, to sprout in positive situation (e.g. water, temperature and aeration) leads to seed dormancy (Bewley, 1997; Finch-Savage and Leubner-Metzger, 2006). To recognize the types of the key controller(s) that inhibit(s) the beginning of germination (dormancy) that initiate the germination practice and their communal interface are question in dormancy and germination study.

Germination is most important and sensitive stage in the life process of a seed bearing plant. Germination behaviour of Sesbania seeds could be improved either via diminishing the latency phase otherwise improving the eminence of seed batch. Seed component tissues that have been used to infer the involvement in dormancy obligation can be arrange into somatic, molecular and genetic groups on the basis of experimental approaches. To use embryos otherwise physically erase the protective tissues testa and pericarp housing caryopses in grass breed are somatic approaches used alternatively. To deduce the occurrence of embryo or coatimposed dormancy the naked caryopses or isolated embryos were germinated on a special medium, as succeed in oat, barley, Arabidopsis, wheat and rice (Takahashi, 1963; Morris et al., 1989; Foley, 1992; Wang et al., 1995; Lee et al., 2010). Botumile et al., (2020) studied the highest mean germination percentages for S. galpinii (92-100\%) were observed for seeds treated with sulphuric acid $(15,30,45$ and 60 minutes). For $V$. robusta, mechanical scarification resulted in the highest mean germination percentage (96\%), and the boiling water treatments, except for the treatment with 24 hours of cooling down, resulted in the lowest mean germination percentage. The two study species possess seed coat imposed dormancies that require pre-sowing seed treatments. Based on the results, the best treatments to release dormancy in both $S$. galpinii and $V$. robusta are sulphuric acid and mechanical scarification, as these yielded the highest, fastest and most uniform germination of seeds.

Chemical treatment also enhances the germination rate in different seeds. Moreover, research in laboratory, greenhouse and field conditions conducted by Oliveira et al., (2012) indicated that the success of local seed germination in the field has a low frequency. In array to recognize the probable function of different ecological aspect for efficient farming of Sesbania spp. it is extremely significant to follow seed germination necessities. Inspite of the potential uses of Sesbania spp. in agriculture and other field, scarce data is accessible on their agrobotanical character together with seed dormancy, germination and seedling properties. Hence, in the current research seed germination behavior in four Sesbania spp. growing in different parts of India was evaluated by using different physical and chemical treatments. 


\section{Materials and Methods}

Seeds of four Sesbania spp. viz., Sesbania sesban, S. grandiflora, S. aculeata and Sesbania rostrata were collected during January, 2016 from Tamil Nadu Agricultural University, Coimbatore, Tamil Nadu. They were individually thrashed on paper and seeds in good physical shape were chosen by removing the trash and broken seeds (Plate 1). After washing with distilled water, constant moisture of seeds were obtained by putting in sunlight for 2-5 days and placed in airtight containers for further study.

Around 30-40 seeds from each Sesbania spp. without any previous treatment were rinsed in distilled water (DW). After that seeds were soaked in $25 \mathrm{ml} \mathrm{DW}$ flask up to $24 \mathrm{hr}$ and placed consistently on a layer of moistened cotton bed in glass petri plates and incubated at $28 \pm 2^{\circ} \mathrm{C}$ including $12 \mathrm{hr}$ photoperiod up to 7 days in growth chamber for germination. Growth chamber was maintained for relative humidity and temperature. Germination of seeds was considered on the basis of coming out of radical not less than $2 \mathrm{~mm}$ from the seed coat. Using randomized design the germination behavior of Sesbania seeds against different treatments was assessed regularly. Temperature treatment of seeds was done by preheated in petri plates up to 30-60 min. in an oven at 40,50 and $60^{\circ} \mathrm{C}$. Sulfuric acid treatment of Sesbania spp. seeds was performed with concentrated sulfuric acid $(98 \%)$ for various time interval $(5,10,15$ and $20 \mathrm{~min}$ ), then seeds were made acid free by rinsing (8-10 times) in DW to make sure whole elimination of acid. Ethanol treatment of seeds was performed by sopping wet in ethyl alcohol (70 and 100\%) for $5 \mathrm{~min}$, followed by 8-10 times rinsing in DW. For potassium nitrate treatments seeds soaking with various concentration $(0.2,0.3,0.4,0.5$ and $0.6 \%$ ) of $99 \%$ potassium nitrate were performed for $24 \mathrm{hr}$ followed by (8-10 times) rinsing in DW. Seeds with different therapy were permitted to grow on $1 \%$ agar medium plates. Percentage of cumulative germination (CG) of seeds was estimated on a daily basis up to 7 days (Bewley and Black, 1994):

$\mathrm{CG}(\%)=\left(\sum n \div N\right) \times 100$

(Where, $n$ is the number of seeds germinated at each day and $N$ is the total number of seeds sown). In control and physical scarification methods seed germination and seedling dimensions were calculated.

\section{Results and Discussion}

Despite the dormancy of Sesbania seeds, considerable germination was observed due to soaking in the distilled water. The maximum germination of seeds was observed on treatment with temperature at $50^{\circ} \mathrm{C}$ in four Sesbania spp. In India throughout summer, the seeds of Sesbania spp. in soil seem to be affected as a result of high temperature resultant in enhanced germination on the commencement of monsoon. Scarification has an imperative function among the diverse protocol used to reduce dormancy in legume seeds (Hartmann et al., 1997). Usually performed scarification processes consist of rasping with heat and acid treatment. Chemicals those are not growth regulators could enhance metabolic action and encourage germination. Seeds scarification with concentrated sulfuric acid $(20 \mathrm{~min})$, ethanol (100\% for $5 \mathrm{~min})$ and salts $(0.4 \%$ for 5 min) increased seed germination and seedling dimension in four Sesbania spp. seeds. Enhanced germination of Sesbania grandiflora seeds were observed with concentrated sulphuric acid up to $20 \mathrm{~min}$ treatment, which was more than control, soaking, ethanol, potassium nitrate and temperature treatments (Table 1 and Plate 2). In $S$. grandiflora seeds to get better germination, acid-treatment increase 
permeability of seed coat particularly of dormant. Seeds treatment with ethanol (100\% for $5 \mathrm{~min}$ ) resulted excellent germination and sprout development in Sesbania aculeata, $S$. sesban and $S$. rostrata seeds. However, seed germination using treatment with potassium nitrate $(0.4 \%)$ was higher in all four Sesbania spp. studied than other concentrations $(0.2$, $0.3,0.5$ and $0.6 \%$ ) (Table 1).

Table.1 Percentage germination of untreated and treated seeds of Sesbania spp.

\begin{tabular}{|c|c|c|c|}
\hline Species & \multicolumn{2}{|c|}{ Treatment } & Germination (\%) \\
\hline \multirow{16}{*}{ Sesbania sesban } & Control & Untreated & 17 \\
\hline & Soaking & Distilled water & 32 \\
\hline & Temperature $\left({ }^{0} \mathrm{C}\right)$ & 40 & 18 \\
\hline & & 50 & 27 \\
\hline & & 60 & 25 \\
\hline & Concentrated & 5 & 44 \\
\hline & Sulfuric acid (min.) & 10 & 50 \\
\hline & & 15 & 53 \\
\hline & & 20 & 55 \\
\hline & Ethanol (\%) & 70 & 60 \\
\hline & & 100 & 76 \\
\hline & Potassium nitrate $(\%)$ & 0.2 & 47 \\
\hline & & 0.3 & 49 \\
\hline & & 0.4 & 53 \\
\hline & & 0.5 & 48 \\
\hline & & 0.6 & 45 \\
\hline \multirow{16}{*}{$\begin{array}{l}\text { Sesbania } \\
\text { grandiflora }\end{array}$} & Control & Untreated & 12 \\
\hline & Soaking & Distilled water & 30 \\
\hline & Temperature $\left({ }^{0} \mathrm{C}\right)$ & 40 & 20 \\
\hline & & 50 & 29 \\
\hline & & 60 & 26 \\
\hline & Concentrated & 5 & 20 \\
\hline & Sulfuric acid (min.) & 10 & 40 \\
\hline & & 15 & 55 \\
\hline & & 20 & 70 \\
\hline & Ethanol (\%) & 70 & 35 \\
\hline & & 100 & 47 \\
\hline & Potassium nitrate $(\%)$ & 0.2 & 25 \\
\hline & & 0.3 & 27 \\
\hline & & 0.4 & 32 \\
\hline & & 0.5 & 26 \\
\hline & & 0.6 & 22 \\
\hline \multirow[t]{6}{*}{ Sesbania aculeata } & Control & Untreated & 30 \\
\hline & Soaking & Distilled water & 52 \\
\hline & Temperature $\left({ }^{0} \mathrm{C}\right)$ & 40 & 33 \\
\hline & & 50 & 40 \\
\hline & & 60 & 37 \\
\hline & Concentrated & 5 & 60 \\
\hline
\end{tabular}




\begin{tabular}{|c|c|c|c|}
\hline & Sulfuric acid (min.) & $\begin{array}{l}10 \\
15 \\
20\end{array}$ & $\begin{array}{l}68 \\
72 \\
80\end{array}$ \\
\hline & Ethanol (\%) & $\begin{array}{c}70 \\
100\end{array}$ & $\begin{array}{l}75 \\
82\end{array}$ \\
\hline & Potassium nitrate $(\%)$ & $\begin{array}{l}0.2 \\
0.3 \\
0.4 \\
0.5 \\
0.6\end{array}$ & $\begin{array}{l}51 \\
57 \\
63 \\
59 \\
53\end{array}$ \\
\hline \multirow[t]{6}{*}{ Sesbania rostrata } & Control & Untreated & 38 \\
\hline & Soaking & Distilled water & 52 \\
\hline & Temperature $\left({ }^{0} \mathrm{C}\right)$ & $\begin{array}{l}40 \\
50 \\
60\end{array}$ & $\begin{array}{l}30 \\
43 \\
38\end{array}$ \\
\hline & $\begin{array}{l}\text { Concentrated } \\
\text { Sulfuric acid (min.) }\end{array}$ & $\begin{array}{c}5 \\
10 \\
15 \\
20\end{array}$ & $\begin{array}{l}40 \\
55 \\
68 \\
73\end{array}$ \\
\hline & Ethanol (\%) & $\begin{array}{c}70 \\
100\end{array}$ & $\begin{array}{l}62 \\
70\end{array}$ \\
\hline & Potassium nitrate (\%) & $\begin{array}{l}0.2 \\
0.3 \\
0.4 \\
0.5 \\
0.6\end{array}$ & $\begin{array}{l}50 \\
52 \\
60 \\
56 \\
51\end{array}$ \\
\hline
\end{tabular}

Plate.1 Dry seeds of Sesbania sesban (a) Sesbania grandiflora (b) Sesbania aculeata and (c) of Sesbania rostrata (d)

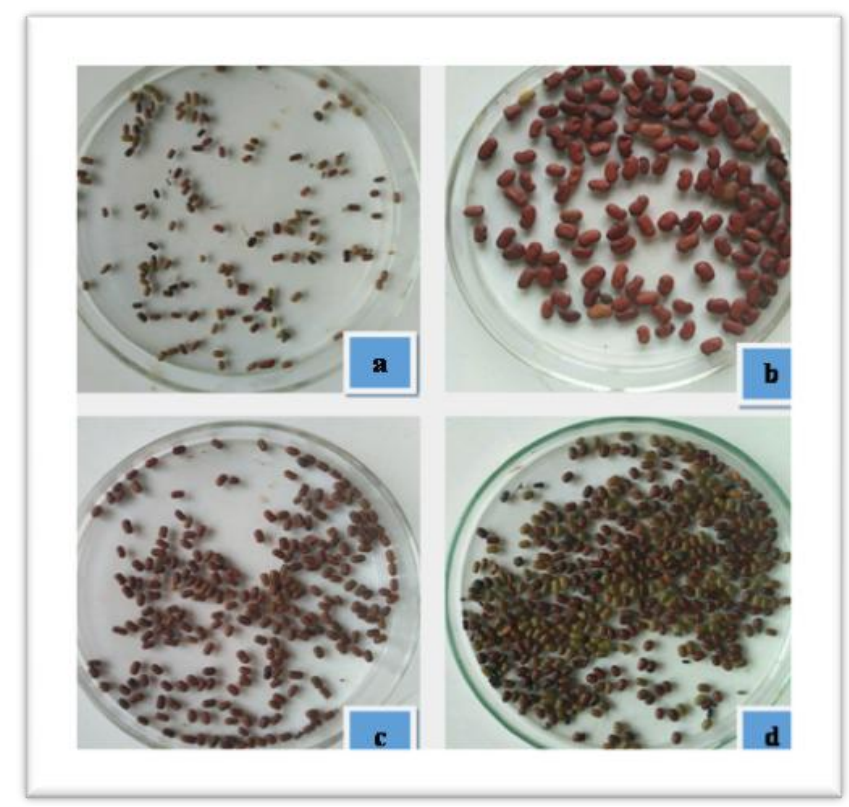


Plate. 2 Germination behavior of Sesbania sesban treated with ethanol (70\%) (a) Sesbania grandiflora using concentrated sulphuric acid (20 min) (b) Sesbania aculeata with potassium nitrate $(0.4 \%)$ and (c) of Sesbania rostrata at $50^{\circ} \mathrm{C}$ temperature (d) on $1 \%$ agar medium plates

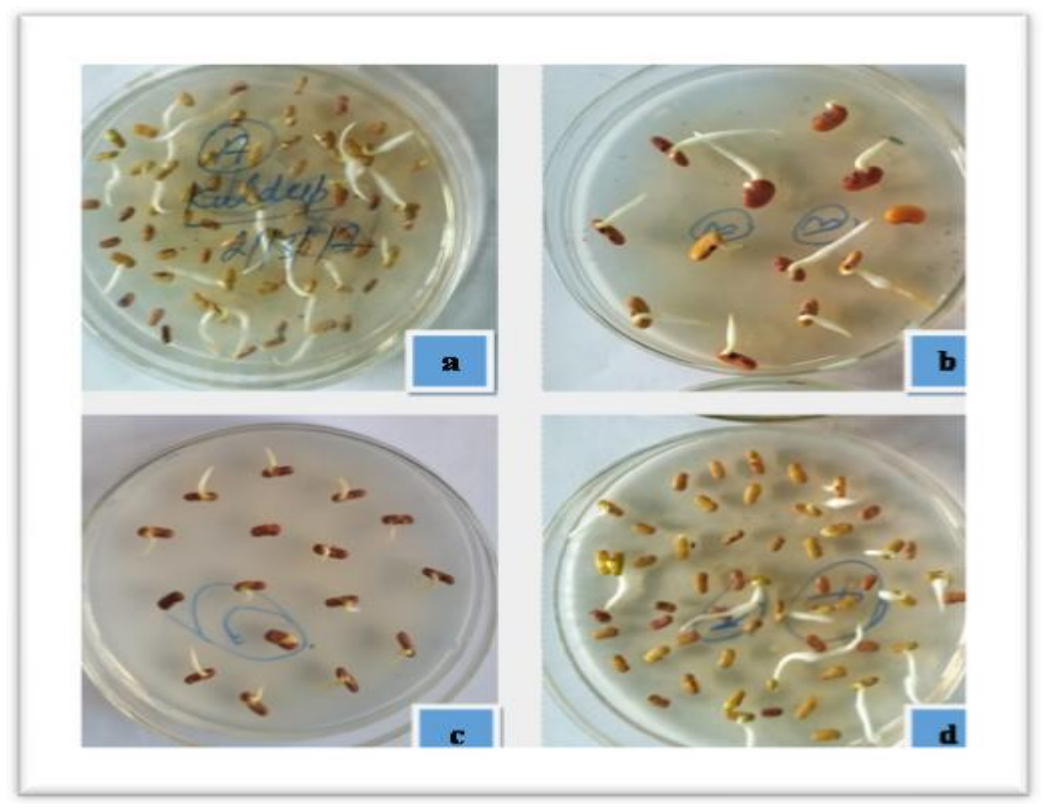

Although potassium nitrate is normally cause seed germination but their function is not clear. Seeds of S. sesban and S. aculeata are less dormant than $S$. grandiflora followed by S. rostrata. Similarly Pollard et al., (2011) reported that pea-shaped seeds (e.g. $S$. formosa, S. tripettii, S. drummondii, $S$. grandiflora and $S$. speciosa) germinates superior as compare to cylinder-shaped seeds (e.g. S. cannabina, S. sesban, S. aculeata, $S$. javanica, S.egyptica, $S$. rostrata and $S$. exaltata). In Sesbania rostrata and $S$. grandiflora seed dormancy could be due to the seed coat rigidity. The temperature is very influential on seed germination. Shonjani (2002) reported that environmental conditions, for instance temperature, $\mathrm{pH}$, low oxygen concentration, salinity, sediment accumulation and flooding influence seed germination in swampland. Ambika et al., (2014) reported the effect of seed size on seedling vigour and seed yields. Overall, meager soaking in distilled water, seeds of all plants resulted considerable germination. The highest seed germination was also achieved in
S. grandiflora and $S$. rostrata with concentrated sulfuric acid proceed by soaking in ethanol. Seeds of $S$. sesban and S. aculeata showed the highest germination on treatment with ethanol. Shreelalitha et al., (2015) concluded that seed germination rate of Sesbania could be enhanced by soaking the seeds in distilled water for 24 hours or in a solution of GA3 (250 mg/L) for 24 hours. Chanda et al., (2017) reported that seed size, both length and/or width, highly correlated with root and seedling length, base diameter, vigour index and biomass yield of Sesbania spp. Anshari et al., (2018) also reported germination time of 13 local plant species in two hydroseeding mulches containing diverse tackifier concentration, along with determined the optimal hydroseeding mulch media composition. Eight out of 13 species could be germinated: S. timorense, S. indicus, C. cajan, C. pallida, $T$. arundinaceae, $S$. sesban, $S$. grandiflora and $T$. purpurea. The fluid M1 medium was best for seeds germination of $S$. grandiflora $(35 \%)$ and S. sesban (50\%), while the thicker M2 medium was favorable for 
seeds germination of $S$. timorense $(50 \%)$ and S. sesban (67\%) in 13 DAS. Carruggio et al., (2020) investigated morpho-anatomical traits and dormancy-breaking requirements in two taxa of the genus Bituminaria: the widespread $B$. bituminosa and the point endemic $B$. basaltica germination tests after mechanical, thermal, and chemical scarification treatments for seed dormancy breaking. Differences in morpho-anatomical traits were found, with $B$. basaltica having a thicker palisade cell layer and $B$. bituminosa showing larger pods. All of the scarification treatments proved to be able to break physical dormancy, with mechanical and chemical scarification being the most effective methods in both species.

In conclusion the results from the present study show that the barrier to germination of seeds of Sesbania grandiflora, S. sesban, S.aculeata and S.rostrata is the hard seed coat, which prevents water uptake. Hence, before the seeds can germinate, they require mechanisms, which overcome this barrier. The results also indicated that the barrier can be removed through different scarification pre-sowing treatments. Sesbania sesban, $S$. aculeata and $S$. rostrata immersion in ethanol (100\% for 5 min.) showed highest seed germination. The future characterization of additional Sesbania genetic resources from other soil resources will have remarkable importance.

\section{Acknowledgement}

We thank the Department of Microbiology, CCS Haryana Agricultural University, Hisar, India for providing necessary facilities for this research work.

\section{References}

Ambika, S., Manonmani, V. and Somasundaram, G. (2014) Review on the effect of seed size on seedling vigor and yield. Research Journal of Seed Science, 1, 1-8.

Anshari, M.F., Fernandes, A.A.R. and Arisoesilaningsih, E. (2018) Comparing seeds germination of some local plant species on two hydroseeding mulches for post mining revegetation. Journal of Degraded and Mining Lands Management, 5 (2), 1103-1110.

Bewley, J.D. (1997) Seed germination and dormancy. Plant Cell, 9, 1055-1066.

Bhat, K.G. (2003) Flora of Udupi. Indian Naturalist, Udupi, Karnataka, India, p. 597.

Botumile, A., Teketay, D., Mojeremane, W. and Mathowa, T. (2020) Overcoming seed dormancy of Senegalia galpinii and Vachellia robusta through scarification pre-sowing treatments. The Journal "Agriculture and Forestry" Casopis "Poljoprivreda $i$ šumarstvo", 66(1), pp.153- 169.

Carruggio, F., Onofri, A., Impelluso, C., Giussodel Galdo, G., Scopece, G. and Cristaudo, A. (2020) Seed Dormancy Breaking and Germination in Bituminaria basaltica and $B$. bituminosa (Fabaceae). Plants, 9(9), p.1110.

Chanda, S.C., Mridul, A.M., Sagar, A. and Sarwar, A.K.M.G. (2017) Germination and seedling growth of Sesbania species as influenced by seed size. Progressive Agriculture, 28(4), 316322.

Duke, J.A. and Polhill, R.M. (1981) Seedlings of leguminosae. In Polhill, R.M. and Raven, P.H. (Eds.), Advances in Legume Systematic - Part II. Kew: Royal Botanic Gardens. pp. 941-949.

Finch-Savage, W.E. and Leubner-Metzger, G. (2006) Seed dormancy and the control of germination. New Phytol, 171, 501523.

Foley, M.E. (1992) Effect of soluble sugars and gibberellic acid in breaking 
dormancy of excised wild oat (Avenafatua) embryos. Weed Science, 40, 208-214.

Hartmann, H.T., Kester, D.E., Davies, F.T., Jr. and Geneve, R.L. (1997) Plant Propagation: Principles and Practices. Prentice-Hall, Inc., Englewood Cliffs, New Jersey. Sixth edition.

Lee, K.P., Piskurewicz, U., Tureckova, V., Strnad, M. and Lopez-Molina, L. (2010) A seed coat bedding assay shows that RGL2-dependent release of abscisic acid by the endosperm controls embryo growth in Arabidopsis dormant seeds. Proceedings of the National Academy of Sciences USA, 107, 1910819113.

Morris, C.F., Moffatt, J.M. Sears, R.G. and Paulsen, G.M. (1989) Seed dormancy and responses of caryopses, embryos, and calli to abscisic acid in wheat. Plant Physiology, 90, 643-647.

Oliveira, G., Nunes, A., Clemente, A. and Correia, O. (2012) Testing germination of species for hydroseeding degraded Mediterranean areas. Restoration Ecology, 20(5), 623-630.

Pollard, M.A., Fischer, P. and Windhab, E.J. (2011) Characterization of galactomannans derived from legume endosperms of genus Sesbania
(Faboideae). Carbohydrate Polymers, 84, 550-559.

Shonjani, S. (2002) Salt sensitivity of rice, maize, sugar beet and cotton during germination and early vegetative growth (Master's thesis). Giessen Institute of Plant Nutrition, Justus Liebig University, Germany.139 pp.

Shreelalitha, S.J., Sridhar, K.R. and Sukesh, S. (2015) Seed dormancy and germination in two wild genotypes of Sesbania of the southwest mangroves in India. International Journal of Agricultural Technology, 11(4), 895902.

Takahashi, N. (1963) Studies on the dormancy of wild rice seeds Part 2. Role of seed coat, embryo and endosperm in dormant seeds, pp. 75-85 in The 241st Report of the Institute for Agricultural Research, Tohoku University, Sendai, Japan.

Taylorson, R.B. and Hendricks, S.B. (1977) Dormancy in seeds. Annual Review of Plant Physiology, 28, 331-354.

Wang, M., Heimovaara-Dijkstra, S. and Duijn, B.V. (1995) Modulation of germination of embryos isolated from dormant and nondormant barley grains by manipulation of endogenous abscisic acid. Planta, 195, 586-592.

\section{How to cite this article:}

Kuldeep Singh, Ruchi Sharma, Rajesh Gera, Jagdish Parshad and Shahid Ahmad Padder. 2020. Effect of Different Chemical Treatments for Breaking Seed Dormancy in Sesbania spp. Int.J.Curr.Microbiol.App.Sci. 9(10): 2640-2647. doi: https://doi.org/10.20546/ijcmas.2020.910.318 